NBER WORKING PAPER SERIES

\title{
EFFECTS OF FEDERAL POLICY TO INSURE YOUNG ADULTS: EVIDENCE FROM THE 2010 AFFORDABLE CARE ACT DEPENDENT COVERAGE MANDATE
}

\author{
Yaa Akosa Antwi \\ Asako S. Moriya \\ Kosali Simon \\ Working Paper 18200 \\ http://www.nber.org/papers/w18200
}

\author{
NATIONAL BUREAU OF ECONOMIC RESEARCH \\ 1050 Massachusetts Avenue \\ Cambridge, MA 02138 \\ June 2012
}

The authors would like to thank three anonymous reviewers for very helpful comments that substantially improved the paper. We are grateful for helpful comments from Joel Cantor, David Figlio, Seth Freedman, Robert Kaestner, Genevieve Kenney, Rick Kronick, Alan Monheit, Michael Morrisey, Benjamin Sommers, and seminar audiences at the Boston University/Harvard/MIT Health Economics seminar series, University of New Hampshire Economics Department, Urban Institute, U.S. Department of Justice, Virginia Commonwealth University School of Public Health, University of Pennsylvania, Miami University Ohio Department of Economics, Purdue University Economics Department, Carnegie Mellon University Health Economics Brown Bag seminar and the fall 2012 Association for Public Policy Analysis and Management (APPAM) conference. The authors have no conflicts of interests to disclose related to this paper. The views expressed herein are those of the authors and do not necessarily reflect the views of the National Bureau of Economic Research.

NBER working papers are circulated for discussion and comment purposes. They have not been peerreviewed or been subject to the review by the NBER Board of Directors that accompanies official NBER publications.

(C) 2012 by Yaa Akosa Antwi, Asako S. Moriya, and Kosali Simon. All rights reserved. Short sections of text, not to exceed two paragraphs, may be quoted without explicit permission provided that full credit, including $(\mathrm{C}$ notice, is given to the source. 
Effects of Federal Policy to Insure Young Adults: Evidence from the 2010 Affordable Care Act Dependent Coverage Mandate Yaa Akosa Antwi, Asako S. Moriya, and Kosali Simon

NBER Working Paper No. 18200

June 2012

JEL No. I13,I28

\title{
ABSTRACT
}

We study the health insurance and labor market implications of the recent Affordable Care Act (ACA) provision that allows dependents to remain on parental policies until age 26 using data from the Survey of Income and Program Participation (SIPP). Our comparison of outcomes for young adults aged 19-25 with those who are older and younger, before and after the law, shows a high take-up of parental coverage, resulting in substantial reductions in uninsurance and other forms of coverage. We also find preliminary evidence of increased labor market flexibility in the form of reduced work hours.

\author{
Yaa Akosa Antwi \\ Indiana University \\ Purdue University-Indianapolis \\ 425 University Blvd \\ CA 530 \\ Indianapolis, IN 46202 \\ yakosaan@iupui.edu \\ Asako S. Moriya \\ School of Public and Environmental Affairs \\ Indiana University \\ 1315 E. Tenth Street Room 441 \\ Bloomington, IN 47405 \\ asako.moriya@gmail.com
}

Kosali Simon

School of Public and Environmental Affairs

Indiana University

Rm 359

1315 East Tenth Street

Bloomington, IN 47405-1701

and NBER

simonkos@indiana.edu 
The earliest insurance expansion provision of the March 2010 Affordable Care Act (ACA) to take effect mandated that health plans and insurers that offer dependent coverage allow children to stay on their parent's health insurance plans until their 26th birthday (U. S. Public Health Services Act section 2714). This mandate became effective on the next plan renewal date after September 22nd 2010. This extension of dependent coverage was an important aspect of the health reform package, since young adults have historically high uninsurance rates (Levy, 2007). Full-year uninsurance among young adults, defined in this paper as those aged 19-25 years, was 37 percent based on Current Population Survey (CPS) data for 2008. The comparable statistics were 18 percent for those aged 12-18 years and 25 percent for those aged 26-35 years.

There are several reasons why the difficulty faced by young adults in obtaining insurance is a significant economic and social concern. For one, research has shown that uninsurance among young adults causes large reductions in their use of health care services (Anderson, Dobkin and Gross, 2012). Second, young adults may find themselves insured by sources that are less than ideal because of "job-lock" (Madrian, 1994) or imperfections in the market for individuallypurchased coverage. Lack of health insurance is also tied to financial problems (Himmelstein et al., 2005). For these reasons, allowing young adults to remain on their parents' health insurance plans may improve their health care use, their resulting health, their human capital and job experience accumulation and their finances.

Substantial federal and state public policy attention has been devoted to increasing children's health insurance access in the past through Medicaid and the Children's Health Insurance Program (CHIP), but eligibility for these public plans phases out by age 19 (Anderson, Dobkin, and Gross, 2012; Levine, McKnight, and Heep, 2011). Insurer mandates to cover older dependent children past age 18 had been popular among states prior to 2010, albeit in a weaker form relative to the ACA provision (Levine, McKnight, and Heep, 2011; Monheit et al., 2011).

In this paper, we examine the ways in which the availability of extended parental health insurance coverage for young adults has affected their health insurance outcomes, as well as the ramifications of those effects on labor market behavior. Using data from the Survey of Income and Program Participation (SIPP) covering August 2008 to November 2011, we ask how the ACA provision has affected the insurance rates, insurance substitution patterns and job flexibility of young adults from the pre-enactment period (August 2008 to February 2010) to the postenactment period (March 2010 to September 2010) as well as the staggered implementation 
period (starting October 2010). Our empirical design, which uses the federal mandate as a quasiexperiment to estimate differences-in-differences (DD) regressions that compare those in the age group targeted by the mandate (19-25 year olds) to those slightly younger and older (16-18 and 27-29 year olds) allows for a more comprehensive analysis of the impact of the ACA than previous efforts.

We make five main contributions to the literature. First, the SIPP monthly data allow us to carefully trace the effects of the law starting in the post-enactment period through the end of the staggered implementation, relative to the pre-enactment period. Previous studies have not been able to separate out these effects. Second, we leverage the rich health insurance details included in the SIPP to examine uninsurance as well as several different sources of coverage. Most prior studies have tended to examine private coverage as a whole, rather than examine the opposing incentives at play for parental versus own forms of private coverage. As a third contribution, we examine the heterogeneity of impact by considering the expected marginal costs and benefits of obtaining new coverage (such as availability of parental health insurance, and own health status). We also conduct a comprehensive analysis of take-up, examining the characteristics of young adults who remained uninsured even though their parents have employer-sponsored insurance (ESI). Fourth, we present the first estimates of the effects of the mandate on the labor market flexibility of young adults, an important objective of the law. Fifth, we consider implications of our results for future studies on other provisions of the ACA.

We find that the 2010 ACA provision had an immediate impact on parental ESI coverage of young adults even before implementation officially started in late September 2010. During March 2010-September 2010, parental ESI rose by approximately 10 percent among young adults relative to their baseline rate prior to March 2010. Once the period of staggered implementation commenced, parental ESI among young adults rose by 30 percent (a 7.0 percentage-point increase) on average during October 2010 to November 2011. When examining partial data from the period after full implementation (October-November 2011) we find that the rate was 10.2 percentage-points, a 43.6 percent increase over the pre-enactment period. Our estimate of the average impact of the provision, based on the period after the implementation began, translates into 2.06 million young adults adding parental ESI as a result of the law. This is close to the high-range estimate ( 2.12 million) predicted by the federal government prior to the law's implementation. 
The increase in parental ESI drew from both the uninsured and the otherwise-insured populations. Our main results show that the average impact of the law post-September 2010, relative to the pre-enactment period, was a 3.2 percentage-point increase in insurance; the 7.0 percentage-point increase in dependent coverage is associated with decreases of 3.1 and 0.8 percentage-points in own-name ESI and individually-purchased non-group insurance, respectively. These results translate into a 9.5 percent fall in uninsurance on average during the period after implementation began. When examining just the last two months of our data, we find that the full effect is a 2.6 percentage-point increase in any insurance; the 10.2 percentagepoint increase in dependent coverage is associated with decreases of 5.7 and 1.1 percentagepoints in own-name ESI and individually-purchased non-group insurance, respectively. Our estimate of the average impact of the provision, based on the period after the implementation began, translates into 938,000 fewer uninsured young adults as a result of the policy. This estimate is within the range of effects predicted by the federal government prior to the ACA's implementation (Federal Register, 2010) which ranged from 0.19 million to 1.64 million. Further investigation of our take-up effects among individuals for whom we observe parental insurance status suggests that the ACA erased about one-third of the uninsurance among targeted individuals with parental ESI.

We also find evidence consistent with increases in dependent-plan coverage among those with higher marginal benefits and lower marginal costs of obtaining new coverage. For example, increases in dependent coverage were greater among those whose parents already covered other dependents, greater for Whites relative to non-Whites, for single individuals relative to married individuals, and for non-students relative to students. Men and older young adults (aged 23-25) experienced greater decreases in uninsurance than women and those aged 19-22. We find no statistically significant difference in the impact of the provision on young adults who reside in states with or without some form of prior state dependent-coverage mandate. Through descriptive examination of those who remain uninsured despite the fact that their parents have ESI, we find that their characteristics indicate lower socioeconomic status. In the concluding sections, we discuss the broader implications of these results, including implications for future aspects of the ACA.

Aside from improved health, one of the most significant aims of this law was to "...permit greater job mobility (for young adults)... as their insurance coverage would no longer be tied to 
their own jobs or student status..." (p.21, Federal Register, 2010). The ACA presents a compelling setting to investigate "job-lock." Our results provide preliminary evidence that young adults worked fewer hours and were less likely to work full-time jobs following the mandate. It is possible that the reduced reliance on own-name ESI as a result of the law could result in increased job mobility in the future as the job market recovers, a topic to be examined with future data.

\section{Background and Motivation}

Before moving on to describe our study in more detail, it is useful to place the ACA policy in the context of earlier state and federal actions regarding insurance markets. The use of privateinsurer mandates has been a popular way for governments to increase health insurance provision without much new public spending (Jensen and Morrissey, 1999). In these cases, the relatively small increases in public spending result from shifting compensation packages from wages to health insurance, which is tax exempt. As noted by Summers (1989), mandates could be justified on paternalistic grounds as employers and employees may otherwise opt for lower levels of coverage and later experience remorse. Mandates could also limit the tendency of workers to choose firms that offer coverage for services they value, which drives up employer costs. Mandates, however, are not without welfare costs. To the extent that those who benefit from the greater insurance value conferred by a mandate are not the only ones who pay the additional costs, mandates create inefficiencies (Kolstad and Kowalski, 2012b; Lahey, 2012).

The many differences between recent public policy initiatives aimed at covering younger children and those covering children over age 18 suggest that results from one policy may not be generalized to the other. For instance, younger-child coverage expansions are financed primarily through public funds, while the primary channel for young-adult-dependent mandates is private coverage, which entails much smaller tax subsidies. Another difference lies in the demographic groups targeted. Dependent-coverage provisions impact those whose parents have private insurance, while Medicaid and CHIP policy affects lower-income populations. This has implications for behavioral effects among those who might already be insured as well as for those who are uninsured. Among young adults with parents who were privately insured in 2010, the federal government estimated that only 17 percent were uninsured, while 40 percent were 
covered by own-name private insurance and 14.9 percent had other forms of coverage such as Medicaid or TRICARE (Federal Register, 2010).

Broad insurance mandates to cover populations have been enacted and studied in the past at the state level, most recently in Massachusetts (Kolstad and Kowalski, 2012a) and before that in Hawaii (Buchmueller, DiNardo, and Valletta, 2011), but federal insurance mandates have thus far focused on mandating that private insurers offer coverage for specific services, such as minimum maternity coverage (Gruber, 1994) and minimum postpartum hospital stays (Liu, Dow, and Norton, 2004). These federal insurer mandates have typically occurred after similar laws had gained traction at the state level.

Even though most states had already expanded dependent coverage for young adults before the ACA (Levine, McKnight, and Heep, 2011; Monheit et al., 2011), there are several reasons why studying the impact of the federal expansion of dependent coverage is important. First, state expansions had led to unclear effects on health insurance coverage for young adults, partly because the state laws had several restrictions based on age as well as marital, student, prior uninsurance, and state residency statuses. This is an important area for investigating the relative strength of federal versus state solutions to similar problems. In addition, Internal Revenue Service (IRS) regulations prior to March 2010 stipulated that the exclusion of employer health insurance contributions from taxable income applied only to children under age 19, or under age 24 for full-time students; insurance provided to older dependents would have to be reported as taxable income. Under the ACA, this section of the IRS code was amended effective March 2010 so that the tax exemption applies to children until they turn 27 years of age, regardless of whether they are tax dependents (IRS, 2010a, 2010b). Perhaps most importantly, earlier state laws did not apply to self-insured plans because the Employee Retirement Income and Security Act (ERISA) exempts them from these regulations. About 57 percent of private sector health insurance enrollees were enrolled in self-insured plans in 2010 (AHRQ, 2012). Moreover, it is not clear how well the state provisions were understood by potentially eligible families (Cantor et al., 2012a) while the ACA provisions were widely publicized. Unlike the heavily qualified state laws, the federal insurer mandate applies to all children under the age of 26 , and therefore presents a unique opportunity for studying the effect of a targeted insurance expansion on the coverage and other behaviors of affected individuals. 


\section{A. Prior State-Level Private Insurance Mandates}

Currently, there are on average over 40 private-insurer coverage mandates in each state (Bunce, 2012). Most mandates target services or providers that should be covered, rather than coverage of sub-populations. State mandate activity specific to young-adult-dependent coverage, which started in 1995 with legislation in Utah, yielded the limited provisions described above. Two papers (Levine, McKnight, and Heep, 2011; Monheit et al., 2011) used CPS data to evaluate the insurance effects of state laws for dependent coverage but reached different conclusions. Monheit et al. (2011) find no evidence that uninsurance was reduced, while Levine, McKnight, and Heep (2011) find a 3 percentage-point drop in uninsurance. There are many small differences between their approaches: the demographic definitions of the treatment and control groups differ; they have slightly different characterizations of state laws and samples of the CPS data; they have somewhat different outcome and control variables; and Levine, McKnight, and Heep (2011) draw their conclusions from a triple-difference estimate using a within-state control group, while Monheit et al. (2011) estimate a DD where the within-state control group is included along with the out-of-state control group. ${ }^{1}$ Although it is beyond the scope of our paper to determine the most appropriate approach to this question, the lack of consensus motivates our need to perform several specification checks with alternative control groups when studying the federal law.

\section{B. ACA Dependent Care Provision}

The dependent coverage expansion of the ACA was implemented in 2010, starting with a revision of the IRS rules in March. Starting on September 23rd 2010, insurers offering dependent-coverage policies that included children were required to allow older children to remain enrolled up to their 26th birthday, as of the next renewal date of the plan. The Veterans Administration allowed dependent children to remain on parental policies in a manner similar to other employers (typically allowing older dependents coverage until they were 19 years, or 24 years for full-time students), and Medicaid and CHIP defined children as those under age 19. As

\footnotetext{
1 Five states (IL, MD, MN, MO, and MT) are included in Monheit et al. (2011) as reform states but not in Levine, McKnight, and Heep (2011). Four of those states implemented their laws in January 2008. Washington is classified as a reform state in the Levine, McKnight, and Heep (2011) analysis but not in the Monheit et al. (2011) analysis. Levine, McKnight, and Heep (2011) use ages 19-24 as their base sample while Monheit et al. (2011) use ages 19-29 as six reform states had extended the affected age beyond 24 years. Private correspondence with the authors and our own investigations with CPS data suggest that differences are not attributable to any particular difference in approach.
} 
mentioned above, recent state laws have changed the availability of parental coverage for older children, with thirty states implementing some form of the dependent-coverage mandate prior to the ACA.

While some insurers chose to comply with the ACA dependent coverage provision sooner than September 2010, insurers and employers could legally wait until the start of the next plan year after September 22nd 2010. ${ }^{2}$ Although the plan renewal date could be as late as September 22nd 2011, most employer plans start in January or July, with the vast majority being in January (Cronin, 2012). Until 2014, grandfathered employer plans in existence as of March 23rd 2010 are still allowed to refuse coverage to age-qualified dependent children whose own employers offered them health insurance, although it is unknown to what extent this provision is enforced. An estimated 56 percent of insured workers are in grandfathered plans as of 2011 (KFF 2012). Other than this stipulation, employer and individual market policies are required to include children regardless of marital status, student status, co-residence with parents, tax-dependent status, or other limitations associated with earlier state attempts to expand dependent coverage. ${ }^{3}$ Employers were required to send written notification of a special open enrollment period during which newly-eligible children could be added to policies. There was widespread publicity regarding the new law, including an active "Young Adult Coverage" Facebook page created by the White House Office of Public Engagement.

There are two published regression-based analyses on the effect of the ACA mandate on health insurance status (Cantor et al., 2012b; Sommers and Kronick, 2012). Both use CPS data through 2010 (reported in 2011), which does not allow one to separate insurance estimates from early versus later in the year. This is a drawback of CPS data, as early 2010 represents a pre-policy time period. A Centers for Disease Control and Prevention (CDC) report (Cohen and Martinez, 2012) contains descriptive statistics showing the number of young adults with coverage through 2011. Using quarterly means from the National Health Interview Survey (NHIS) spanning 2010 to the first quarter of 2011, Cohen and Martinez (2012) report that the percentage of uninsured young adults decreased by 3.5 percentage-points, from 33.9 percent in 2010 to 30.4 percent in

\footnotetext{
2 Health and Human Services Secretary Sebelius requested insurers to implement the provision sooner than September 23rd 2010 in order to avoid disenrolling and re-enrolling children who would graduate from college in May 2010; several major insurers agreed to this request (Federal Register, 2010).

3 Tricare also voluntarily added the extension to age 26 for military insurance starting January 2011. http://www.navy.mil/search/display.asp?story_id=58052
} 
the first quarter of 2011. They also show quarterly mean uninsurance rates for all older adults. Finally, they show means for private coverage, without separating own-name ESI (substitution) from parental coverage (take-up) effects.

In contrast to the studies above, our paper uses an approach that allows us to discern between early and intermediate effects of the law, to decompose the effects according to different sources of health insurance held by young adults and according to the expected marginal costs and benefits of new coverage, including whether parents have ESI. Our study can also shed some light on the later-stage effects of the law, as we have two months of post-full implementation data, whereas most previously published studies present effects for 2010 alone. Finally, in addition to analyzing the effects of the ACA mandate on the health insurance choices of young adults, our paper also provides the first examination of whether labor market behavior is affected.

\section{Hypotheses}

Our first hypothesis is that, given several health insurers announced intentions to act before the actual implementation date, we should expect that impact of the law was visible prior to September 2010. However, the hypothetical direction of anticipatory behavior is not always clear. For example, Alpert (2012) finds that seniors reduce their use of certain medications in anticipation of Medicare Part D implementation. Thus it is possible that young adults would reduce their insurance coverage in the period between enactment and implementation due to their anticipation of imminent eligibility for new health insurance coverage.

We next test whether we observe insurance effects consistent with predictions from a very simple conceptual framework of health insurance and labor market behavior. We hypothesize that effects will be concentrated among families with lower marginal costs for adding dependents on parental employer health insurance policies, and among those with higher marginal benefitse.g. those in worse health. In our simple conceptual framework, young adults derive utility from insurance coverage $I$, job match $t$, which is a function of whether they have access to outside sources of health insurance, and from consuming a composite good $Y$. They maximize $U(I, Y, t)$ constrained by the available set of insurance choices, including access to dependent health insurance through parents, their health status, and human capital. 
Through the ACA policy change, some young adults whose parents have an employer policy could be added as dependents for low marginal costs. Shifting from uninsured to insured status increases the utility of the formerly uninsured young adults, particularly those in worse health. Utility also increases for those who switch away from their current insurance source toward coverage under their parents' policy if the current source is inferior in cost and quality or if parental coverage would allow them to consider future job changes or decrease their work hours free of the worry of losing ESI. Even if there is an increased cost to parents for adding young adults in terms of higher premiums or lower wages in the long run, these costs may not always come out of the dependent's pocket. Thus, we anticipate reductions in own-name individual and employer coverage. It is unclear whether there are advantages to dropping public health insurance, as cost sharing is typically very low in public insurance. There are few avenues to public coverage for the population targeted by this provision. However, if the quality of public insurance is perceived as sufficiently inferior, there could also be substitutions away from public insurance. In their study of the impact of state dependent-coverage laws on young adults, Levine, McKnight, and Heep (2011) find suggestive evidence of this "reverse crowdout" phenomenon, whereby expansion of private coverage substitutes for public coverage.

We expect that the availability of parental insurance affects insurance choices primarily for those whose parents already had access to ESI prior to the law, as it is likely to be prohibitively expensive for most parents to change jobs in search of new coverage for older dependents. But parents may decide to add offered ESI, and we test this empirically. Furthermore, if the parent already has a full-family policy that covers younger children, the marginal cost of adding an older child is close to zero. By law, insurers are not allowed to charge more for the newlyeligible dependents due to their age than they already do for other dependent children.

In summary, we hypothesize that the ACA could lead to a reduction in uninsurance among young adults starting before the implementation of the law. We expect that dependent coverage through parental policies could increase partly as a result of young adults opting for the new coverage in place of other sources of coverage for which they pay more. Coverage increases should be largest among those with lower marginal costs for adding extra dependents to existing employer policies and among those in worse health, for whom coverage offers higher marginal benefits. We also expect that, for targeted young adults who hold jobs primarily for health 
insurance benefits, the flexibility created by the mandate will act as encouragement to drop out of the labor force, switch jobs, or switch from full-time to part-time work.

\section{Data}

We investigate the impact of the ACA dependent coverage mandate using data from the SIPP 2008 panel. The SIPP is a household-based nationally-representative longitudinal survey of the civilian non-institutionalized population, conducted by the U.S. Census Bureau. The 2008 panel interviewed approximately 50,000 households for four years, starting in September 2008. In any given month, interviewers visit one-fourth of the sample to collect retrospective responses for the last four months. Data are released roughly nine months after collection, making the survey a valuable tool for the early evaluation of recent public policies. We use data from August 2008 to November 2011 including the latest wave of SIPP data that has been released. The 2008 panel is well-timed for the evaluation of the dependent coverage provision, since it contains data covering the period prior to the March 2010 ACA enactment, from March 2010 to the September 2010 start of implementation, and at least an additional year of data after September 2010.

SIPP offers several advantages for our purposes. First, it contains point-in-time insurance questions, which allow us to investigate differential responses to the law following enactment and implementation. The SIPP also allows us to distinguish ESI own-name coverage from ESI dependent coverage; we expect the two to move in opposite directions, but in some other data sets private insurance is reported as just one category.

Second, the SIPP follows individuals longitudinally, as long as they do not move into military barracks or become institutionalized. This allows us to gather more information on them than would be obtained from cross-sectional surveys. When a young adult moves out of his or her parents' household, the survey continues to follow both parties. We determined that for about two-thirds of all 19-25 year olds, we have contemporaneous parental health insurance characteristics even for the post-reform period. Most but not all of this subsample are currently sharing the primary address with their parents. This subsample of data allows us to estimate the impact of the provision on young adults aged 19-25 years whose parents have ESI. Because those with whom we can match parental information are likely not a representative sample, we consider these data in a separate analysis rather than in our base model. Our base sample consists of observations for those aged 16-29 years, except for 26 year olds who are not clearly in either 
the treatment or the control group. To reduce recall bias, we only use data collected on the most recent reference month of the wave, although we estimate models with all months as a specification check. We create binary dependent variables to indicate having any insurance, dependent ESI from parents, own ESI, own-name non-group individual coverage, and public coverage. ${ }^{4}$ As with all longitudinal surveys, there is a concern about attrition and non-response during follow-up rounds. The SIPP program goes to considerable effort to maximize follow up, and sampling weights are produced to reduce the influence of attrition on estimates, but concerns regarding nonresponse bias may still persist. We use survey weights in all results presented.

\section{Method}

Estimating the effects of the policy requires a strategy that can isolate the impact of the ACA on the insurance coverage of young adults from contemporaneous changes in health insurance markets. Since the policy's effects are delineated by age, our main identification strategy is to use a control group of younger (16-18 year olds) and older individuals (27-29 year olds), relative to our treatment group of 19-25 year olds. This strategy rests on the assumption that the control group will account for other time-varying factors that would have led the treatment group to experience different insurance rates after reform. Those in the older control group may be more similar to young adults when it comes to making their own insurance and employment choices. However, the younger control group may reflect the changing circumstances of employer dependent coverage, which has been decreasing in generosity over time (Vistnes et al., 2012), thus we test the sensitivity of results to the choice of control group.

While the post reform suitability of the control group is an untestable assumption, there are several ways to test the extent to which treatment and control group insurance rate trends were similar in the pre-reform period. In Figure 1, we plot unconditional insurance coverage rates for control and treatment groups in order to visually examine the period before and after the ACA enactment. This figure shows that while there is generally a similar pattern prior to the ACA passage, the two lines diverge sharply following the law's enactment. Relative to the control group, the treatment group insurance rates start to increase from the time of enactment, although

\footnotetext{
4 Even though the law also applied to non-group coverage that parents bought, we did not create a separate column for this form of coverage as it is relatively rare. We also did not separate out spousal dependent coverage, although in a robustness check we tested whether this form of coverage was affected. Because these two forms of insurance are not separately identified, the coefficients across the columns will not add up to the uninsurance coefficient.
} 
the larger increases happen after the third quarter of 2010. The insurance rate of the control group on the other hand does not experience dramatic changes, but increases in the fourth quarter of 2011, which could reflect the impact of national labor market improvements. We perform a formal statistical test for equality of trends using data from August 2008 to February 2010. We estimate a model with indicators for having any health insurance coverage or dependent coverage through a parent as dependent variables. This model uses the same control variables as our main model, which we describe below, except that the key variable of interest is an interaction between the linear time trend and the treatment group dummy instead of the usual differences-in-differences variables. We conclude from our results included in Appendix Table A1 that although the control and treatment groups have very different levels of insurance coverage, there is no statistically detectable difference in their trends prior to the policy change, conditional on control variables included in the model.

\section{[Insert Figure 1 Here]}

In Figure 2, we plot coverage under dependent policies by age group and time. This shows that the age profile of dependent insurance changed markedly for those in the 19-25 age range, as we move from enactment to implementation and beyond. However, a simple visual inspection of the data is unlikely to reveal the causal effects of the ACA; for example, the mid-year dip in insurance rates for the treatment group in Figure 1 may be due to college graduation and loss of insurance, which does not affect the control group. Figure 2 provides a strong visual confirmation that the law had a direct and large impact on the parental ESI coverage rate of our treatment group. To estimate the effects more precisely, we estimate the DD regression model below:

(1) $Y_{\text {igst }}=\alpha+\gamma$ Treat $_{g}+\delta$ Implement $_{t}+\vartheta$ Enact $_{t}+\eta\left(\right.$ Treat $_{g} *$ Implement $\left._{t}\right)+$ $\sigma\left(\right.$ Treat $_{g} *$ Enact $\left._{t}\right)+\mathbf{X}_{i g s t} \boldsymbol{\beta}+\tau_{t}+\zeta_{s}+\varepsilon_{i g s t}$,

where $Y_{\text {igst }}$ represents insurance coverage or labor market outcomes for individual $i$ in age range $g$, state $s$ and time $t, \mathbf{X}_{i g s t}$ represents other individual-level factors that affect insurance, Implement $_{t}$ represents a dummy for the period after staggered reform enactment commenced in 
September 2010 through the latest period of data available, November 2011, and Treat ${ }_{g}$ represents a dummy for being in the 19-25 age range (relative to those aged 16-18 and 27-29). The interaction of Implement $t_{t}$ and Treat $_{g}$ captures the average impact since staggered reform implementation started, by comparing insurance coverage during this period relative to coverage during the months before enactment, among the treatment group relative to the control group. In later specifications, we break this period down further.

\section{[Insert Figure 2 Here]}

To examine the anticipatory changes in insurance coverage that happened after enactment (March 2010) but before implementation began (September 2010), we add a dummy variable,

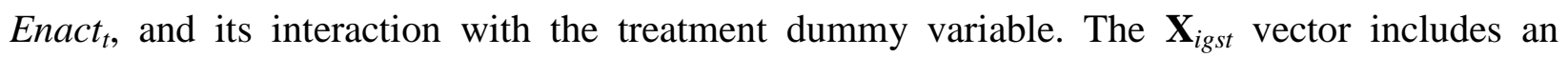
indicator for age, gender, race/ethnicity, marital status, student status, household income as a share of federal poverty line, and its squared term. This vector also includes monthly linear national and state-specific time trends, the monthly state unemployment rate, and an interaction of the treatment dummy variable and the state unemployment rate. ${ }^{5}$ We also include dummy variables for year and calendar month in $\tau_{t}$, state fixed effects in $\zeta_{s}$ to account for differences by state in dependent coverage laws prior to the ACA, and we cluster standard errors at the level of the state.

Following the earlier literature in dependent coverage laws (e.g. Levine, McKnight, and Heep, 2011), we use linear probability models due to the ease of interpretation and computation of marginal effects of interacted variables in models with clustered standard errors. As an alternative, we also estimated our main models using a logistic regression specification with standard errors calculated as suggested by Ai and Norton (2003). We estimate model (1) first for all targeted young adults and their control group, and then separately for those with different self-reported health statuses and other demographic characteristics to explore the heterogeneous impact of the law.

Even if it appears that past trends in insurance do not differ between control and treatment groups, a DD method does not guarantee that trends in the control group will capture all other unobserved factors that could affect the treatment group's insurance status, absent the policy

\footnotetext{
${ }^{5}$ We have also estimated models that used a one year lag of the unemployment rate, in case the unemployment rate in the state may be affected by the ACA provision, but find the results to be unaffected.
} 
change. For example, job opportunities might have worsened for young adults relative to others. We lessen this concern somewhat by choosing a control group consisting of both older and younger age groups relative to the treatment group and allowing the state monthly unemployment rate to be correlated with the treatment group dummy. We address this further with a triple difference strategy estimated among the subsample of individuals matched to parental information. Those young adults whose parents do not have ESI are unaffected by the law directly, but are arguably likely to experience the same exogenous health insurance trends.

We considered two alternative estimation strategies which we concluded were inappropriate for this situation. For one, we investigated the possibility of using a regression discontinuity approach. Unfortunately, we found the discontinuity in insurance rates at the top end of the age distribution of 26 years or at age 19 did not change substantially enough to enable an RD design. This is visible in Figure 2. Another potentially attractive approach is to use states with prior dependent coverage mandates as a control group for the impact of the federal law. However, this approach presents several challenges since state laws were substantially weaker than the federal law, and it is not possible to tell which young adults in a state are affected by the federal law but were not affected by prior state laws. For example, even if a prior state mandate covered nonstudent unmarried young adults between the ages of 19-22 years, more than half of these cases would be self-insured plans exempt from the law.

\section{Results}

Table 1 shows descriptive statistics for our sample of 16-29 year olds. We first show the statistics for the full sample, and then break them down by treatment group (19-25 year olds) versus the two age groups included in the control category (16-18 year olds and 27-29 year olds). On average during our time period, there are similarities as well as large differences between the groups in level terms. As noted earlier, uninsurance rates tend to be highest among those in the treatment-group age range. From Table 1, we see that 67.8 percent of 19 to 25 year olds have

insurance of any kind compared to 87.0 percent and 69.3 percent for 16 to 18 year olds and 27 to 29 year olds respectively. Race and ethnicity are similar across the groups. Notice also that since education and employment progress with age, older young adults are more likely to be employed and are better educated than those who are younger. Finally, younger adults are more likely to describe their health status as excellent. 


\section{[Insert Table 1 Here]}

Our main DD results from Equation (1) presented in Table 2 show the effects of the law's implementation period as well as the anticipatory response of young adults and insurers prior to implementation. Since the two different policy dummy variables featured in this table are mutually exclusive, each result tells us the average effect on insurance rates during that phase of the policy, relative to before the March 2010 enactment date. Below the regressions results in Table 2, we show the mean insurance rates by control and treatment groups, before enactment in March 2010 and after implementation in September 2010. In anticipation of the implementation of the law, the results presented in the first row show that dependent health insurance coverage for young adults increased by 2.4 percentage-points (10.2 percent relative to the base) relative to the control group; this increase is offset by a 1.7 percentage-point decrease in ESI coverage in own name. There is a marginally significant 1.1 percentage-point decrease in governmentprovided health insurance as well. During this initial period, we also find no statistically significant change in individually-purchased coverage or in uninsurance rates. Thus, these anticipatory responses to reform led to an increase in dependent coverage but did not translate into overall gains in health insurance coverage.

\section{[Insert Table 2 Here]}

The second row of Table 2 shows our DD estimates of the implementation of the ACA provision. We find that it led to a 3.2 percentage-point reduction in uninsurance for 19-25 year olds, relative to the control group, after conditioning on all other variables in the model. This represents a 9.5 percent reduction in the rate of uninsurance for young adults, as their uninsurance rate was 33.5 percent (100-66.5) prior to ACA enactment. Focusing on the later columns of Table 2, we find a 7 percentage-point increase in dependent coverage, a 0.8 percentage-point reduction in non-group insurance and a 3.1 percentage-point reduction in ownname ESI. These results imply that with an estimated 29.5 million young adults in the US (Federal Register, 2010), about 938,000 young adults gained health insurance on average in the period after implementation began, as a result of the mandate. As a comparison, this estimate of overall gains in health insurance is between the 0.65 million mid-range and the 1.64 million 
high-range estimates anticipated by the federal government prior to the implementation of the law (Federal Register, 2010). ${ }^{6}$

In Table 3, we estimate an alternate specification in which we study the timeline of the law in more detail. We split the post-September 2010 dates into three segments: October 2010-February 2011; March 2011-September 2011; and October 2011-November 2011. The first period captures the bulk of plan anniversary dates, since it encompasses January 2011. The second comprises the remainder of the implementation period, and the third represents a period after all plans were expected to comply. As the rotational structure of the SIPP leads to only a fourth of our sample being interviewed each month, only half the sample is represented in the last period. Although this is a random half of the sample, we are conservative in our use of equation (1) as our main specification where the post-implementation period is captured by one dummy variable.

\section{[Insert Table 3 Here]}

As expected, Table 3 shows successively higher average take-up rates in the later time periods, relative to pre-enactment. The full-implementation effect on parental ESI coverage is now 43.6 percent, corresponding to a 10.2 percentage-point increase. This translates into 3 million adults, and is higher than the high-range federal estimate of 2.12 million (Federal Register, 2012). The estimated results on uninsurance, however, are sensitive to the time periods chosen for comparison. The full implementation effect here shows a 2.6 percentage-point decrease in uninsurance, while the largest effect occurred toward the middle part of 2011, at 3.2 percentagepoints, although the three estimates are not statistically different from each other. It is noteworthy that this 3.2 estimate for mid-2011 is similar to the 3.5 percentage-point estimate in Cohen and Martinez (2012), which takes a different approach but uses data as of mid-2011.

The reduction in other forms of coverage in Table 3 increases over time, with individual coverage dropping by 1.1 percentage-points (nearly one-third drop from the initial level; roughly 324,500 individuals) and own-ESI dropping by 5.7 percentage-points (close to 28 percent of the

\footnotetext{
6 The federal estimates were made using 2004-2006 Medical Expenditure Panel Survey Household Component (MEPS-HC). They projected
low, mid and high estimates for the number adding parental insurance and the number of newly insured young adults, depending on three take-up scenarios. These are $0.7,1.24$ and 2.12 million, and $.019, .65$ and 1.64 million respectively. They assume no changes will occur in own-name employer insurance or government provided insurance, and that the number who might switch from own-name non-group policies to parental policies is 0.55 million at most (but do not provide a range for this estimate).
} 
pre-ACA level; roughly 1.68 million individuals) at the end of the implementation period, relative to before the passage of the ACA. Thus our estimate of the full impact of the provision, based on the two months of post-full-implementation data available in the SIPP, translates into 778,800 young adults fewer uninsured as a result of the policy. As with our Table 2 estimate, this also falls within the scope of the mid- to high- range estimates anticipated by the federal government (Federal Register, 2010).

\section{A. Heterogeneity of Effects}

Although Table 2 presents results for all young adults, we expect there to be heterogeneity in the impact of the law along several dimensions. First, we estimate our main results by age (19-22 years and 23-25 years separately), gender, race/ethnicity, marital status (married versus nonmarried) and student status (full-time students versus others) and perform statistical tests of the difference between each pair. These demographic dimensions are associated with different circumstances that might affect the availability of parental insurance as well as take-up and substitution behaviors. As Table 4 indicates, we find evidence that the increase in parentalemployer-dependent coverage was statistically significantly higher for Whites, non-married individuals and non-students than for their counterparts. A larger increase in dependent coverage for Whites is consistent with patterns of higher availability of (parental) ESI (KFF, 2009).

\section{[Insert Table 4 Here]}

Married young adults are more likely to be financially independent of parents than single young adults, which possibly explains the lower rise in dependent coverage observed for them. ${ }^{7}$ Since full-time students had greater access to parental employer health insurance due to prior IRS laws, the difference in take-up we estimate between the two groups is not surprising. We find no statistically significant differences in parental employer dependent coverage by gender and age. However, men experienced statistically significant greater reductions in uninsurance than women; the coefficient for men (0.042) was about twice as large as that for women (0.020). This is a meaningful result given the high rate of uninsurance among young men.

\footnotetext{
${ }^{7}$ We also tested whether married young adults are likely to drop their spousal coverage as a result of the law. It is plausible that young adults might find it advantageous to switch from family coverage to single coverage if one spouse is able to obtain insurance as a dependent on his or her parents' policy. In unreported tables, we find no evidence to suggest that spousal health insurance decreased, even when we restricted the sample to only married individuals.
} 
Correspondingly, young adults aged 23-25 were not statistically significantly different in their change in dependent coverage relative to those who were 19-22 years of age, but experienced greater reductions in uninsurance than their counterparts. ${ }^{8}$

Another dimension along which differences could occur is state of residence. Although the ACA is unprecedented in its expansion of dependent coverage, most states had passed similar laws of varying strength prior to the federal law. We tested separate models in Table 4 for states that had passed some form of law prior to the ACA date of March 2010. ${ }^{9}$ We find that although the effect of the ACA appears slightly larger in states that had not passed reforms relative to states that had passed reforms, the difference between them is not statistically significant. As noted earlier, state level provisions are far weaker than the federal dependent care provision, thus it may not be surprising that these differences are not more pronounced. In fact, it could well be that the unobserved factors that lead some states and not others to adopt state laws might also lead to a smaller reaction to the broader-reaching federal law in states that chose not to pursue any prior action.

We also present results in Table 4 that test the extent to which the law affects populations who may have greater demand for parental coverage due to their health status. The SIPP does not contain measures for the presence of chronic conditions, thus we separate our sample by the selfreported 1-5 health status variable. The best health recorded is "Excellent," followed by "Very Good," "Good," "Fair," and "Poor." Roughly 60 percent of young adults reported that their health status was less than "Excellent," so we use this as our indicator for higher health care demand. When we test the sensitivity of this classification using other cutoffs for health status (such as Excellent and Very Good versus the rest), we find qualitatively similar results. Among those in excellent health, we estimate a larger coefficient on the dependent coverage measure, but the percentage effect is smaller because the base coverage rate (not shown in the table) is smaller among those in worse health relative to those in excellent health. Formal statistical tests of the two coefficients across the specifications for dependent coverage and for coverage from any source indicate they are not significantly different from each other. Testing for differential

\footnotetext{
8 DD tests by age also restricted the control groups correspondingly. Treatment group individuals aged 19-22 used control group individuals aged 16-18 while treatment group individuals aged 23-25 used control group individuals aged 27-29.

9 In classifying states by prior laws, we follow details collected by the National Conference of State Legislatures at http://www.ncsl.org/issues-research/health/mandated-health-insurance-benefits-and-state-laws.aspx, reading the state statutes to resolve any conflicts in state classifications in prior literature. Our final state classification matches Cantor et al, (2012a).
} 
insurance behavior according to additional measures of health status and other demographic factors that signal demand for health insurance deserves further exploration as more ACA provisions are introduced.

\section{B. Triple-Differences Strategy (DDD)}

An advantage of the SIPP over other data sets is the greater availability of information regarding parents' health insurance characteristics, even in cases where children do not reside with their parents. However, we are not able to match anyone who did not reside with their parents at the start of the panel. Appendix Table A2 lists the fraction of young adults for whom we are able to identify whether their parents have ESI, post March 2010. This is 67 percent for the treatment group ages; there is also a substantial fraction of the control group for whom this information is available. Using data on this subset of individuals for whom parental information is available, we implement a DDD estimation strategy and present results in Table 5. We define the affected group as those whose parents have ESI (and are in the relevant age range) and use young adults whose parents do not have ESI as a further control group. Note that the entire effect

of the law on dependent insurance comes only from those whose parents have ESI, as the dependent variable is otherwise zero.

\section{[Insert Table 5 Here]}

Since parental information is not known for all young adults, we consider the specification in Table 2 to be our main approach. There are two other reasons we do not consider the DDD as our base approach; parents' own coverage may be affected by policy, and there may be selection involved in whether a young adult lives with his or her parents. For example, when we statistically test health status differences between the groups, we find that 54.9 percent of those for whom we have parental information describe their health as less than "Excellent" while 65.9 percent of those for whom we have no parental information do so. Before proceeding to the DDD, for comparison, we first estimate the DD model we use for our main results on the aforementioned subsample. Compared to Table 2, in Appendix Table A3 we find no statistically significant difference for any source coverage and dependent coverage, but a statistically significantly smaller reduction in own-name ESI. 
The DDD results in Table 5 show a higher increase in dependent coverage through parents (9.6 percentage-points; this difference is statistically significantly different from the DD estimate in Table 2), a marginally statistically significant reduction in own-name individual coverage, no statistically significant result on own ESI, and a 6.7 percentage-point increase in coverage from any source. Given that the baseline uninsurance rate among the treatment group is 20.7 percent (fourth row from the bottom of Table 5), this indicates that the ACA reduced uninsurance among the targeted population by about one third. Later in the paper, we study the characteristics of the remaining two-thirds of this targeted population, and possible implications of the grandfathered plan rules. The implied take-up effects among the uninsured here are comparable to estimates from other expansions although they are for a very different context; Gruber and Simon (2008) find that the CHIP expansions during 1996-2002 were associated with an overall take-up of 7 percent across all children, but nearly one-third for uninsured children.

One possible confounding factor in our DDD analysis is that parents may themselves seek ESI once they are able to retain older dependents on their policies, if such coverage is more valuable to them. If this is the case, then our DDD control and treatment groups would change in composition along with the policy and contaminate the study design. We approach this possibility in two ways. First, we re-estimate Table 5 using information on parental health insurance plans from the start of the panel, before the law began. We find that the results were statistically identical to the current Table 5 (except for one coefficient in the fourth column, which is not statistically significant in Table 5). However, since this potentially introduces measurement error, we use current parental information in Table 5 but formally test whether parents' health insurance decisions were affected. In Appendix Table A4, we test whether there is evidence of greater access to ESI after the enactment of the ACA provision among parents of young adults aged 19-25 with the corresponding control group and explanatory variables as our main DD model in Table 2. Our results indicate no evidence of such an effect.

With the richness of the parental information available in the SIPP we are able to extend our analysis in two additional ways. One is to explore take-up by asking questions about those young adults who remain uninsured despite their parents having ESI. We find that even in the last wave of the SIPP data (August-November 2011), by which time the law had been virtually fully implemented, 429 young adults, or 13.1 percent, have parents with ESI but remain uninsured (out of a total of 3,270 whose parents have ESI during that time period), while 2,055 young 
adults are on their parents' employer policies during this time period. In Table 6 we compare the characteristics of these individuals, testing the statistical significance of the sample differences in the last column. From this exercise we see that the two groups are very different along many dimensions that suggest lower socioeconomic status among those who remain uninsured. The uninsured are more likely than those on parental ESI to be older, male, African-American or Hispanic, not full-time students, in worse health, to have lower family income, and live apart from their parents.

\section{[Insert Table 6 Here]}

Even within the group of young adults with access to parental health insurance, there are differences in the marginal costs of adding a young adult to an insurance plan, based on the type of coverage held by parents. If a parent holds a single policy that covers only him- or herself and perhaps a spouse, the cost of adding a young adult dependent may be high, as that involves shifting to a family health insurance policy. On the other hand, a parent who already holds a policy that covers other children should face almost no marginal cost in employee premiums to add a young adult, since the ACA specifically forbids insurers from pricing young adults differently than already covered dependents. We investigate this by looking at young adults who a) had parents with ESI four months prior to the ACA enactment; b) were not on the parents' policy at that time; and c) whose parents hold ESI in the current month. Defining this as the "at risk" population, we consider in Appendix Table A5 the probability that they added parental coverage by the last four months of our data (August to November 2011) according to whether their parents initially had family or non-family coverage. We find that of the 242 whose parents had family coverage initially, 39.2 percent obtained parental coverage after the law, while only 28.0 percent obtained parental coverage among those with non-family coverage.

Although the difference tends toward the expected direction, one might expect the differential to be larger. We also estimate this in the form of a regression and found that adding covariates does not change the results much. Although it is beyond the scope of our paper to explore the take-up differentials fully, we discuss two possibilities that could be explored in future work. One possibility is that using characteristics of parental policies two-and-a-half years prior may introduce measurement error, as many parents may have had to move children on and off policies as children age and change employment and school enrollment statuses, and this 
measurement problem may cause the two statistics to be closer together as we see here. Unreported calculations suggest that the shorter the time period between measuring parental insurance plan characteristics and child insurance, the larger the difference between the single and family take-up rates. The other possible theory relates to why these rates are not higher in both cases; the rule that grandfathered plans may refuse coverage for young adults who are offered coverage through their own employer (even if they do not accept that coverage) may be a limiting factor, and can be tested when more plans lose their grandfathered status. The federal government estimates that about 18 percent of uninsured young adults whose parents have ESI have an ESI offer themselves (Federal Register, 2010).

\section{Robustness Checks}

We estimate several additional models to check the robustness of our results. We estimate models in which we assume falsely that the reform took place in different months prior to March 2010, using data from the period before the ACA enactment. That is, for each of the 17 months between August 2008 and January 2010, we re-estimate Table 2 assuming a placebo date for the ACA law and create a distribution of the results from the replications. We examine the mean and standard deviation of the estimates obtained in Appendix Table A6, relative to the values obtained in Table 2. We find that the placebo tests produce results which are close to zero and are relatively far away from the estimated effects in Table 2. Only two out of a possible 85 estimates are statistically significantly different from zero at even the 5 percent level. This indicates that the results we obtain in Table 2 do not result by chance because trends in treatment and control groups might have been different prior to the law.

Second, we investigate whether the results recorded in our main Table 2 are robust to clustering standard errors at a more aggregated level (year-quarter level) than the state level, following the example in Cameron, Gelbach, and Miller (2008). In this specification, the lefthand variable is the ratio of those with each insurance type calculated at year-quarter level for treatment and control groups. This reduces the number of observations to 28 , and we cluster at year-quarter level for 14 clusters. Using dummy variables for the enactment period (March to September 2010) and another for the period following the start of implementation (October 2010 and onwards), a treatment group dummy and an interaction of these as right hand side variables as in Cameron, Gelbach, and Miller (2008), we show in Appendix Table A7 that adjusting the 
level of clustering and using wild cluster bootstrap-t procedure do not meaningfully affect the statistical significance of the results.

Third, we investigate the impact of estimating marginal effects using a logistic regression, although for ease of interpretation and convergence, and to follow prior literature, we use linear probability models for our main results. We discover that when we use state time trends, our logit models fail to converge. We are also unable to use sample weights in our logit models. However, when we estimate the models without state time trends and without weights, the results we obtain are fairly close qualitatively to the corresponding linear probability model estimates.

Fourth, we explore whether results are sensitive to our choice of control group and treatment group ages. Because of added avenues for public health insurance through the CHIP Reauthorization Act of 2009, which led some states to expand coverage, older teens may not be an ideal control group for young adults. But older young adults aged 27-29 are also not ideal since the effect of the recession may have been less damaging for them than for the treatment group and because they are not able to serve as a control for trends in dependent coverage that might result from rising health insurance premiums. In unreported tables, we find that the outcomes are fairly unchanged when using different control group ages, except that 1) the effect on own-name ESI is slightly smaller (different only at the 5\% level) when only the older control group (ages 27-29) is used and it is slightly larger (different only at the 10\% level) when only the younger control group is used and 2) the effects on any source coverage is larger when only the older control group is used and it is smaller when only the younger control group is used (these differences are statistically significant).

Finally, in exercises also not reported in tables, we found that the results we observe in Table 2 are not statistically significantly different both when we remove states that passed state dependent coverage laws during August 2008 to February 2010, and when we remove Massachusetts from the sample due to prior comprehensive state health reform.

\section{Impact of the Mandate on Labor Market Outcomes}

A potential implication of the availability of new insurance coverage for young adults is that it could affect labor market behavior. The availability of health insurance could influence the decision of young adults to work full-time or part-time, their job choice, their propensity to change jobs and whether they enter or exit the job market (Madrian, 1994; Currie and Madrian, 
1999; and Gruber and Madrian, 2002). As a result of eased "job-lock", we expect to see young adults leaving full time employment altogether, or shifting from full-time to part-time work, moving toward types of employment that do not provide health insurance. Our data allow us to investigate the effects of the federal mandate on whether young adults report working, whether they report working full-time (30 hours or more), their weekly work hours, and their rate of job turnover. We also examine the impact of the mandate on their work schedule flexibility by evaluating the probability that young adults have work hours that vary from week to week.

Our results, starting with the first column of Table 7, show no statistically significant evidence that the mandate affected the probability of employment of young adults. Since the receipt of ESI is usually tied to full-time work, we examined this measure next and find that the law is associated with a reduced prevalence of full-time work by close to two percentage-point (roughly 5.8 percent) during the period after implementation began, relative to pre-ACA enactment. We also find statistically significant evidence for a reduction in hours of work (about a 3 percent reduction); these effects are statistically weaker when we examine log hours as the dependent variable. We next examine whether there is evidence of increased rates of employer or job status change, but find no statistically significant evidence in either column 5 or 6 . We do find, however, some evidence of increased likelihood of reporting that one's job hours vary from week to week. As a robustness check, we excluded the younger control group (aged 16-18 years) and estimate the same specification as Table 7. We find that the magnitudes and significance of the effects are statistically similar, which suggests that our results are not driven by 16-18 year olds among whom labor market attachment is very low. Note, however, that our aim is to provide suggestive evidence on labor markets and not to conduct the same extensive robustness testing as we do above for our insurance outcomes. Thus, these results should be interpreted with caution.

\section{[Insert Table 7 Here]}

Overall, our limited analysis of the labor market impact of the ACA on young adults suggests that the mandate affected the intensive rather than the extensive margin of employment. Even though the decreases in full-time employment and work hours seem small, they are economically meaningful in the context of prevailing job market conditions. One possible reason that we might not see greater evidence of job mobility is that the economic downturn has been particularly 
harsh on young adults' ability to move between jobs since they have less human capital accumulation than the average worker (Danziger and Ratner, 2010). Future research should conduct more in-depth analysis of the labor market impact of the mandate.

\section{Discussion and Conclusions}

We present estimates, using data spanning August 2008 to November 2011, on the health insurance and labor market impact of the 2010 ACA young adult mandate. Our main estimates from a DD model compare outcomes of those aged 19-25 years to those who are slightly older (27-29 years) and slightly younger (16-18 years), during different time intervals. Our results show that the law had an impact on insurance rates even prior to the start of its formal implementation in September 2010. During the implementation period, we find a steady rise in parental ESI, with the average effect after implementation began showing 2.06 million young adults being insured by the policy. Our corresponding central estimates regarding the number of newly insured young adults $(938,000)$ falls between the middle and high range estimates put forward by the federal government prior to ACA implementation. Because the federal estimates were made by assuming that all plans would be grandfathered in 2011, our finding of a reduction in own-name ESI in our paper highlights the importance of understanding assumptions used in federal predictions of ACA effects. Further investigation of this take-up effect suggests that the ACA erased about one-third of the uninsurance among targeted individuals with parental ESI.

Exploring the heterogeneity of impact, we find that those likely to have lower marginal costs and higher marginal benefits regarding the new coverage avenue are more likely to opt for parental coverage. We find no evidence that parents' own coverage was affected by the ACA law. We also show that among those with parental health insurance, there is greater take-up where the marginal cost of adding a dependent to a family policy is lower, although on the flipside there appears to be a substantial number (13.1 percent) of young adults remaining uninsured despite their parents having employer policies. This is possibly due to the fact that grandfathered plans are allowed until 2014 to refuse parental insurance to young adults with ESI offers as well as the fact that the individual mandate is not yet enforced.

This paper provides one of the first comprehensive analyses of an important early provision of the ACA. Based on data from the early release program of the National Health Interview Survey (Cohen and Martinez, 2012), reports have already established that a large number of young 
adults gained coverage between September 2010 and June 2011. Using difference-in- difference regressions, a different data set and a longer time period, our analysis confirms the finding of substantial increases in the coverage of young adults as a result of the ACA provision, but also points to a number of new findings on other outcomes; for example, Cohen and Martinez (2012) do not estimate the number of young adults who added parental coverage.

Many other insurance-related changes are scheduled to be implemented in coming years, and it is important to understand the ways in which the young adult provision might interact with them. We describe here a simplistic exercise to consider the implications for those whose parents do not have ESI, had two other insurance provisions scheduled for 2014 taken effect during the last four months covered by our data. Using our subsample of matched individuals, we find that among those whose parents do not have ESI, 32.9 percent have incomes below 133 percent of federal poverty level (FPL), the level of income that would potentially qualify for expanded adult Medicaid. The corresponding statistic among those whose parents have ESI is 14.9 percent. We also find that a further 53 percent of children whose parents do not have ESI have incomes between 133 percent and 400 percent of FPL and could qualify for some form of subsidy on the state exchanges. The comparable statistic among children of the employer-insured is 26.1 percent.

What these calculations suggest is that, for one, those who are not affected by the young adult dependent provision will be differentially affected by the later insurance expansions. Those who signed up for parental coverage might also be affected, to the extent that they might choose a newly subsidized form of coverage after 2014. If exchange subsidies entice young adults to enter the individual market, this might help to alter the risk pool since the ACA effect of removing young adults from the individual market may have worsened the risk pool, although the welfare effects are not clear without taking into account the insurance rating mechanism in place in a state or the size of the individual market relative to the number of young adults who exited to parental policies. Future changes in the labor market could affect young adults' ability to take advantage of reduced "job- lock" and move to new jobs. Enforcement of the individual mandate could also affect the take-up decisions of those young adults who remain uninsured despite their parents being insured.

Regardless of the precise future path of the young adult parental ESI option, the changes that have already taken place are substantial enough that several more outcomes should be examined, 
such as use of health care; health; financial wellbeing; and social outcomes, such as intergenerational relationships. A full welfare analysis of this provision would also consider how the costs of new coverage were distributed within a firm and the value of reduced "job-lock" for young adults. ${ }^{10}$

\section{REFERENCES}

Agency for Healthcare Research and Quality (AHRQ). 2011. "Percent of Private-Sector Enrollees That Are Enrolled in Self-Insured Plans at Establishments That Offer Health Insurance by Firm Size and Selected Characteristics," (Table I.B.2.b.1), 2010 (July 2011). Medical Expenditure Panel Survey Insurance Component Tables. Generated using MEPSnet/IC. <http://www.meps.ahrq.gov/mepsweb/data_stats/MEPSnetIC.jsp> . Accessed on September 20, 2012.

Ai, Chunrong, and Edward C. Norton. 2003. "Interaction Terms in Logit and Probit Models," Economics Letters, 80 (1): 123-129.

Alpert, Abby. 2012. “The Anticipatory Effects of Medicare Part D on Drug Utilization”. http://ssrn.com/abstract=2161669.

Anderson, Michael, Carlos Dobkin, and Tal Gross. 2012. "The Effect of Health Insurance Coverage on the Use of Medical Services," American Economic Journal: Economic Policy, 4(1): $1-27$.

Buchmueller, Thomas C., John DiNardo, and Robert G. Valletta. 2011. "The Effect of an Employer Health Insurance Mandate on Health Insurance Coverage and the Demand for Labor: Evidence from Hawaii," American Economic Journal: Economic Policy, 3(4): 25-51.

Bunce, Victoria C. 2012. Health Insurance Mandates in the States 2011. Council for Affordable Health Insurance (CAHI) Executive Summary. Available at http://www.cahi.org/cahi_contents/resources/pdf/MandatesintheStates2011ExecSumm.pdf (last accessed on January 27, 2013).

Cameron, A. Colin, Jonah B. Gelbach, and Douglas L. Miller. 2008. "Bootstrap-Based Improvements for Inference with Clustered Errors," The Review of Economics and Statistics,

\footnotetext{
10 The Kaiser Family Foundation estimates the premium impact to be about 1 percent in 2011. (http://www.kff.org/pullingittogether/upload/Methodology-for-Estimating-the-Effect-of-the-Affordable-Care-Act-on-the-Average-Premium-fora-Family-of-Four-in-2011.pdf)
} 
90(3): 414-427.

Cantor, Joel C., Dina Belloff, Alan C. Monheit, Derek DeLia, and Margaret Koller 2012a. “Expanding Dependent Coverage for Young Adults: Lessons from State Initiatives," Journal of Health Politics, Policy and Law, 37(1): 99-128.

Cantor, Joel C., Alan C. Monheit, Derek DeLia, and Kristen Lloyd. 2012b. "Early Impact of the Affordable Care Act on Health Insurance Coverage of Young Adults." Health Services Research, 47(5) 1773-1790.

Cohen, Robin A., and Michael E. Martinez. 2012. "Health Insurance Coverage: Early Release of Estimates From the National Health Interview Survey, January-September 2011," National Center for Health Statistics Issue Brief. Available at http://www.cdc.gov/nchs/data/health_policy/HI_08_to_June11_YoungAdults.pdf (last accessed on January 27, 2013).

Cronin, Christopher. 2012. “Annual Health Insurance Decisions, Uncertain Health Transitions, and Within Year Medical Care Consumption.” Unpublished.

Currie, Janet, and Brigitte C. Madrian. 1999. "Health, Health Insurance and the Labor Market." In Handbook of Labor Economics, ed. Orley C. Ashenfelter and David Card. 3309-3407. North Holland, Amsterdam: Elsevier.

Danziger, Sheldon, and Ratner, David. 2010. "Labor Market Outcomes and the Transition to Adulthood." The Future of Children 20(1): 133-158.

Federal Register 2010. “Group Health Plans and Health Insurance Issuers Relating to Dependent Coverage of Children to Age 26 Under the Patient Protection and Affordable Care Act; Interim Final Rule and Proposed Rule.” Federal Register 75(92): 27122-27140 (May 13, 2010)

Gruber, Jonathan. 1994. "The Incidence of Mandated Maternity Benefits," American Economic Review, 84(3): 622-41.

Gruber, Jonathan, and Madrian, Brigitte C. 2004. "Health Insurance, Labor Supply, and Job Mobility: A Critical Review of the Literature." In Health Policy and the Uninsured, ed. Catherine McLaughlin. 97-178. Washington, D.C.: Urban Institute Press.

Gruber, Jonathan, and Kosali Simon. 2008. "Crowd-Out Ten Years Later: Have Recent Public Insurance Expansions Crowded Out Private Health Insurance?” Journal of Health Economics 27(2): 201-217

Himmelstein, David U., Elizabeth Warren, Deborah Thorne, and Steffie Woolhandler. 2005. 
"MarketWatch: Illness and Injury as Contributors to Bankruptcy," Health Affairs.

Internal Revenue Service (IRS) 2010a. "Tax-Free Employer-Provided Health Coverage Now Available for Children under Age 27," Available at http://www.irs.gov/newsroom/article/0,,id=222193,00.html (last accessed on March 27, 2012 ).

Internal Revenue Service (IRS) 2010b. "Notice 2010-38," Available at http://www.irs.gov/pub/irs-drop/n-10-38.pdf (last accessed on March 27, 2012).

Jensen, Gail A., and Michael A. Morrissey. 1999. "Employer-Sponsored Health Insurance and Mandated Benefit Laws," Milbank Quarterly 77(4): 425-459.

Kaiser Family Foundation (KFF). 2012. "Employer Health Benefits 2011," Available at http://ehbs.kff.org/pdf/2011/EHBS percent202011 percent20Chartpack.pdf Ex 15. Accessed on September 20, 2012.

Kaiser Family Foundation (KFF). 2009. "Role of Health Coverage for Communities of Color," Available at http://www.kff.org/healthreform/upload/8017.pdf. Accessed on September 20, 2012.

Kolstad, Jonathan T., and Amanda E. Kowalski. 2012a. "The Impact of Health Care Reform on Hospital and Preventive Care: Evidence from Massachusetts.” Journal of Public Economics 96(11): 909-929.

Kolstad, Jonathan T., and Amanda E. Kowalski. 2012b. "Mandate-Based Health Reform and the Labor Market: Evidence from the Massachusetts Reform.” NBER Working Paper 17933.

Lahey, Joanna N. 2012. "The Efficiency of a Group-Specific Mandated Benefit Revisited: The Effect of Infertility Mandates," Journal of Policy Analysis and Management, 31(1): 63-92.

Levine, Phillip B., Robin McKnight, and Samantha Heep. 2011. "How Effective are Public Policies to Increase Health Insurance Coverage among Young Adults?" American Economic Journal: Economic Policy, 3(1): 129-156.

Levy, Helen. 2007. "Health Insurance and the Transition to Adulthood," In The Price of Independence: The Economics of Early Adulthood, ed. Sheldon Danziger and Cecilia Elena Rouse. 84-106. New York, NY: Russell Sage Foundation.

Liu, Zhimei, William H. Dow, and Edward C. Norton. 2004. "Effect of Drive-through Delivery Laws on Postpartum Length of Stay and Hospital Charges," Journal of Health Economics 23(1): 129-155.

Madrian, Brigitte C. 1994. "Employment-Based Health Insurance and Job Mobility: Is there 
Evidence of Job-Lock?" The Quarterly Journal of Economics, 109(1): 27-54.

Monheit, Alan C., Joel C. Cantor, Derek DeLia, and Dina Bellof 2011. "How Have State Policies to Expand Dependent Coverage Affected the Health Insurance Status of Young Adults?" Health Services Research, 46(1) Part II: 251- 267.

Sommers, Benjamin D., and Richard Kronick. 2012. "The Affordable Care Act and Insurance Coverage for Young Adults.” Journal of the American Medical Association, 307(9): 913-914.

Summers, Lawrence H. 1989. "Some Simple Economics of Mandated Benefits," The American Economic Review, 79(2): 177-183.

Vistnes, Jessica, Alice Zawacki, Kosali Simon, and Amy Taylor. 2012. "Declines in EmployerSponsored Insurance between 2000 and 2008: Examining the Components of Coverage by Firm Size,” Health Services Research, 47(3): 919-938. 


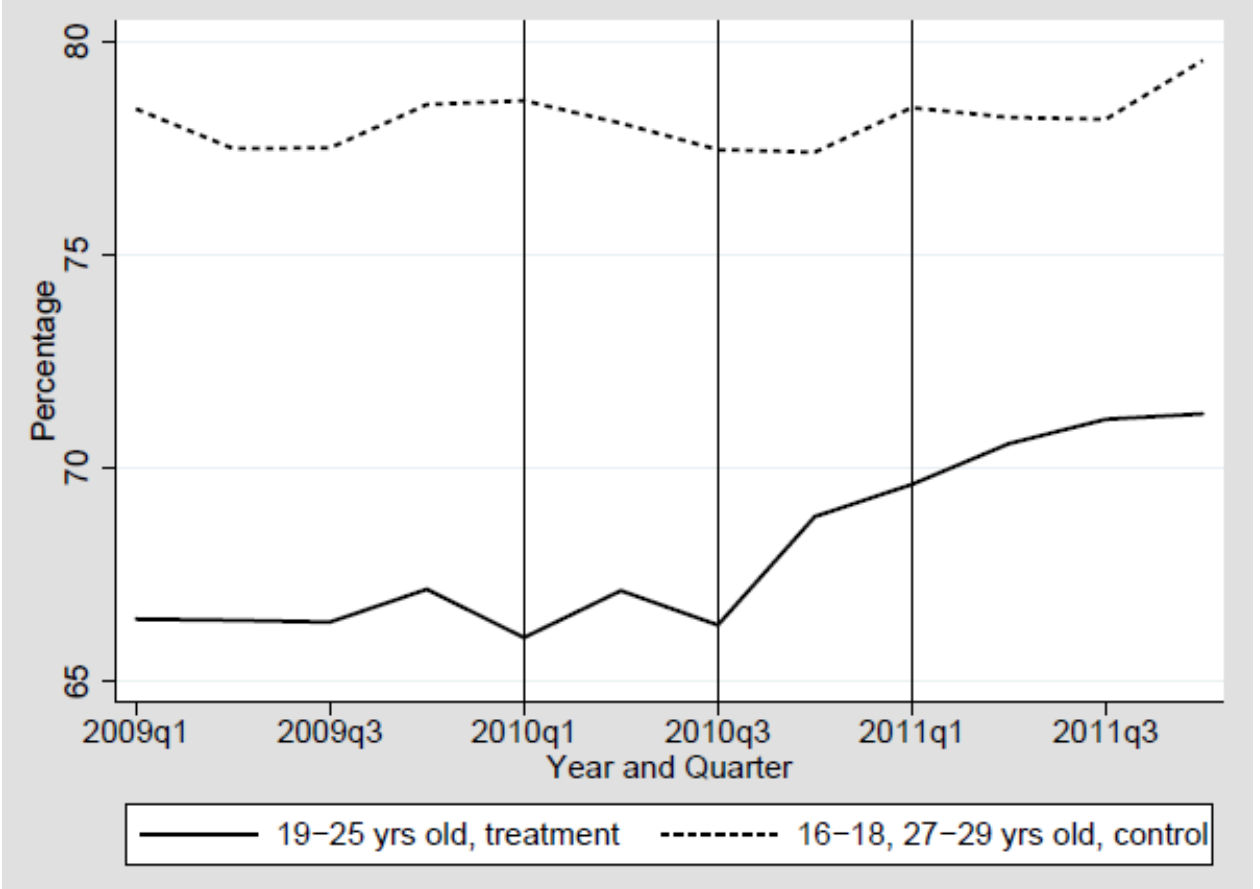

Figure1. Percentage of Young People with Any Insurance Coverage by Treatment and Control Groups

Note: Sample weighted estimates from 2008 SIPP panel, using data from August 2008 to November 2011. The first vertical line indicates the first quarter of 2010 when the ACA was passed, the second vertical line indicates the third quarter of 2010 when the dependent coverage mandate was implemented, and the third vertical line indicates the first quarter of 2011 when most new insurance plan years start after the implementation of the mandate. The estimate for a quarter averages insurance reported as of the three interview months contained in that quarter. We use only the data from October and November 2011 to plot the fourth quarter of 2011since the data for December 2011 is not available in SIPP currently. 


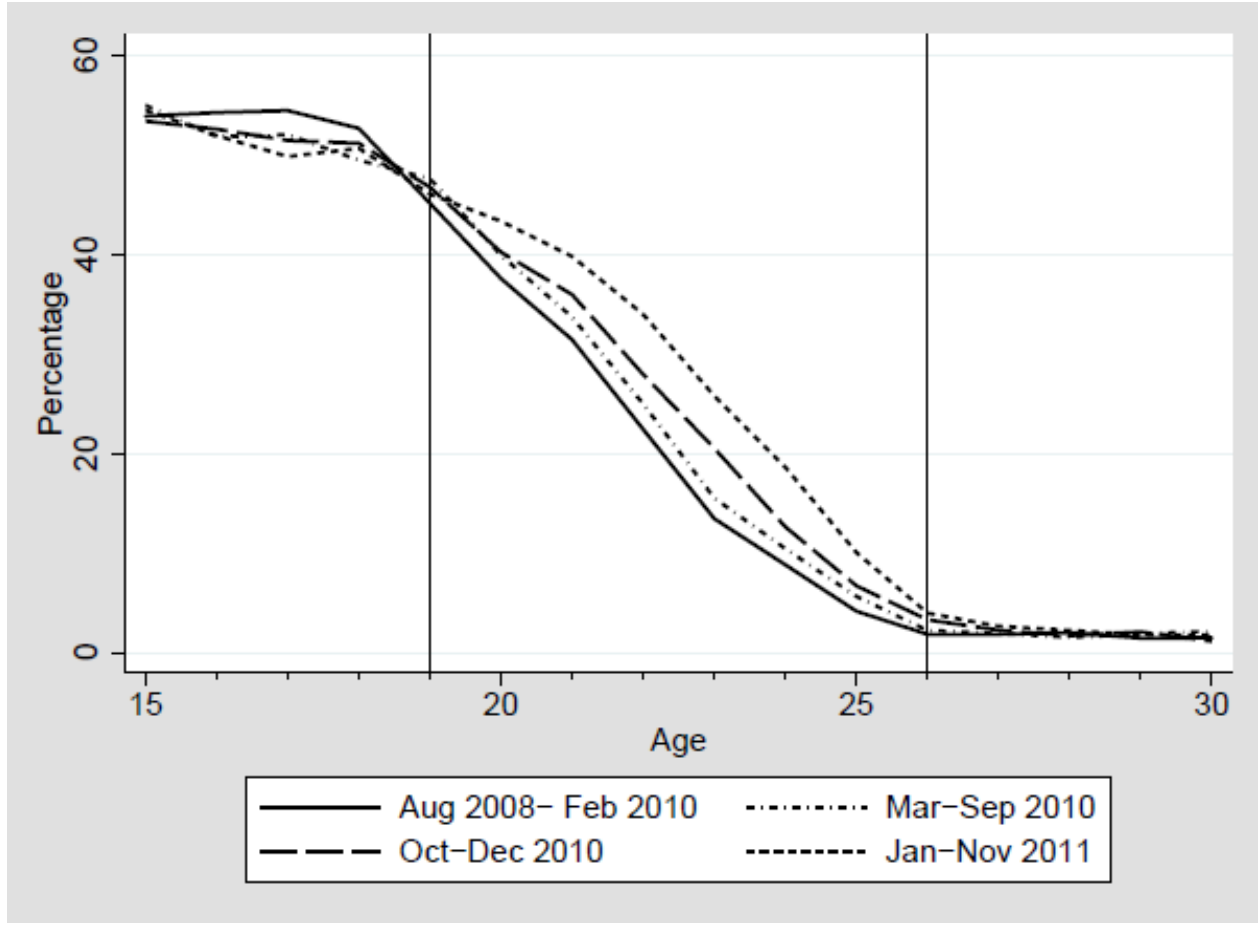

Figure 2. Percentage of Young People Covered by EmPloyer Sponsored Health Insurance as Parents' DePendents Note: Sample weighted estimates from 2008 SIPP panel, using the period from August 2008 to November 2011 as indicated by trend lines. 
TABLE 1. DEMOGRAPHIC, SOCIOECONOMIC AND INSURANCE CHARACTERISTICS

\begin{tabular}{lcccc}
\hline & & & & \\
& All & Age, & Age, & Age, \\
observations & $16-18$ & $19-25$ & $27-29$ \\
\hline Health insurance status & & & & \\
Indicator: covered by any health insurance (HI) & 0.727 & 0.870 & 0.678 & 0.693 \\
Indicator: covered by employer HI as a parent's & & & & \\
dependent & 0.267 & 0.523 & 0.264 & 0.019 \\
Indicator: covered by own employer HI & 0.198 & 0.024 & 0.189 & 0.393 \\
Indicator: covered by individually purchased HI in own & & & & \\
name & 0.028 & 0.011 & 0.032 & 0.036 \\
Indicator: covered by government HI & 0.158 & 0.256 & 0.127 & 0.129 \\
Employment status & & & & \\
Indicator: employed & 0.569 & 0.253 & 0.628 & 0.754 \\
Indicator: unemployed & 0.080 & 0.063 & 0.089 & 0.076 \\
Demographic characteristics & & & & \\
Age & 22.22 & 17.02 & 21.96 & 28.01 \\
Indicator: white & 0.602 & 0.575 & 0.613 & 0.604 \\
Indicator: African-American & 0.136 & 0.146 & 0.135 & 0.127 \\
Indicator: Hispanic & 0.190 & 0.200 & 0.183 & 0.195 \\
Indicator: married & 0.180 & 0.013 & 0.140 & 0.435 \\
Education & & & & \\
Indicator: student & 0.419 & 0.885 & 0.361 & 0.084 \\
Indicator: less than high school & 0.257 & 0.770 & 0.098 & 0.103 \\
Indicator: high-school graduate & 0.272 & 0.178 & 0.325 & 0.245 \\
Indicator: some college & 0.333 & 0.051 & 0.452 & 0.347 \\
Indicator: college graduate & 0.113 & 0 & 0.113 & 0.223 \\
Health status & & & & \\
Self-reported health is less than "excellent" & 0.585 & 0.486 & 0.596 & 0.663 \\
\hline Number of person-month observations & 150,997 & 39,886 & 78,212 & 32,899 \\
Corresponding number of unique persons & 28,853 & 9,618 & 16,803 & 8,441 \\
\hline
\end{tabular}

Note: Sample weighted estimates from the 2008 SIPP, using data from August 2008 to November 2011. Throughout the paper, we use only the 4th reference month within a wave to reduce recall bias. The "All observations" column refers to those aged 16 to 29 years, except for 26 year olds. 
TABLE 2. EFFECT OF ACA on COVERAGE of Young Adults 19-25 YeARS: MAIN DD RESUlTS

\begin{tabular}{|c|c|c|c|c|c|}
\hline & Any source & $\begin{array}{l}\text { Employer } \\
\text { dependent } \\
\text { coverage } \\
\text { (through } \\
\text { parents) }\end{array}$ & $\begin{array}{l}\text { Individually } \\
\text { purchased } \\
\text { insurance in } \\
\text { own name }\end{array}$ & $\begin{array}{l}\text { Employer } \\
\text { own } \\
\text { coverage }\end{array}$ & $\begin{array}{l}\text { Government } \\
\text { provided }\end{array}$ \\
\hline $\begin{array}{l}\text { ACA enactment effect } \\
\text { (March-Sep, 2010) }\end{array}$ & $\begin{array}{l}-0.0018 \\
(0.0064)\end{array}$ & $\begin{array}{l}0.0239 * * * \\
(0.0055)\end{array}$ & $\begin{array}{c}0.0025 \\
(0.0031)\end{array}$ & $\begin{array}{c}-0.0173 * * * \\
(0.0053)\end{array}$ & $\begin{array}{l}-0.0106^{*} \\
(0.0054)\end{array}$ \\
\hline $\begin{array}{l}\text { ACA implementation } \\
\text { effect (October 2010-) }\end{array}$ & $\begin{array}{c}0.0318 * * * \\
(0.0074)\end{array}$ & $\begin{array}{c}0.0702 * * * \\
(0.0069)\end{array}$ & $\begin{array}{l}-0.0080 * * * \\
(0.0023)\end{array}$ & $\begin{array}{c}-0.0312 * * * \\
(0.0060)\end{array}$ & $\begin{array}{l}-0.0025 \\
(0.0058)\end{array}$ \\
\hline $\begin{array}{l}\text { Dependent variable } \\
\text { means } \\
\text { Treatment, before ACA } \\
\text { enactment }\end{array}$ & 0.665 & 0.234 & 0.035 & 0.204 & 0.123 \\
\hline $\begin{array}{l}\text { Control, before } \\
\text { Treatment, after ACA } \\
\text { implementation } \\
\text { Control, after }\end{array}$ & $\begin{array}{l}0.781 \\
0.702 \\
0.783 \\
\end{array}$ & $\begin{array}{l}0.307 \\
0.263\end{array}$ & $\begin{array}{l}0.023 \\
0.026 \\
0.023\end{array}$ & $\begin{array}{l}0.208 \\
0.171 \\
0.210 \\
\end{array}$ & $\begin{array}{l}0.182 \\
0.133 \\
0.200 \\
\end{array}$ \\
\hline
\end{tabular}

Notes: (1) Number of observations is 150,997. (2) Cells of the table contain: coefficients, and standard errors in parentheses. Coefficients in the first row are from the interaction of a dummy variable for treatment group (19-25 years old) and a dummy variable for the period after ACA enactment but before implementation (March-September, 2010); coefficients in the second row are from the interaction of a dummy variable for treatment group and a dummy variable for the period after ACA implementation (October 2010 and onwards). (3) Standard errors are clustered at the state level. All regressions are weighted using person-level weights. (4) Data: pooled waves of the 2008 SIPP panel. We use the data for period from August 2008 to November 2011. The population is young adults aged from 16-29, except for the removal of 26 year olds who are in neither control nor treatment. Only 4th reference month observations from the SIPP are used in the regression. (5) Dependent variables - column 1: indicator variable that equals 1 if individual is covered by health insurance from any source and 0 otherwise; column 2: indicator variable that equals 1 if individual is covered by employer health insurance as a dependent of a parent and 0 otherwise; column 3: indicator variable that equals 1 if individual is covered by individually purchased insurance in own name and 0 otherwise; column 4: indicator variable that equals 1 if individual is covered by employer health insurance in own name and 0 otherwise; column 5: indicator variable for any type of government-provided health insurance. (6) Other regressors are an indicator for the period after ACA enactment but before implementation, an indicator for the period after ACA implementation, an indicator for each year of age, year-specific fixed effects, month-specific fixed effects, time trend, state fixed effects, gender, race/ethnicity, marital status, student status, household income as a share of federal poverty line and its squared term, monthly unemployment at state level, interaction of unemployment and an indicator for treatment group. (7) Means of dependent variables are obtained for treatment and control groups before ACA enactment (before March 2010) and after ACA implementation (after September 2010).

*** Significant at the 1 percent level.

** Significant at the 5 percent level.

* Significant at the 10 percent level. 
TABle 3: EfFect of ACA on Coverage of Young Adults 19-25 YeARs: Three Post-ACA Time Periods, DD RESULTS

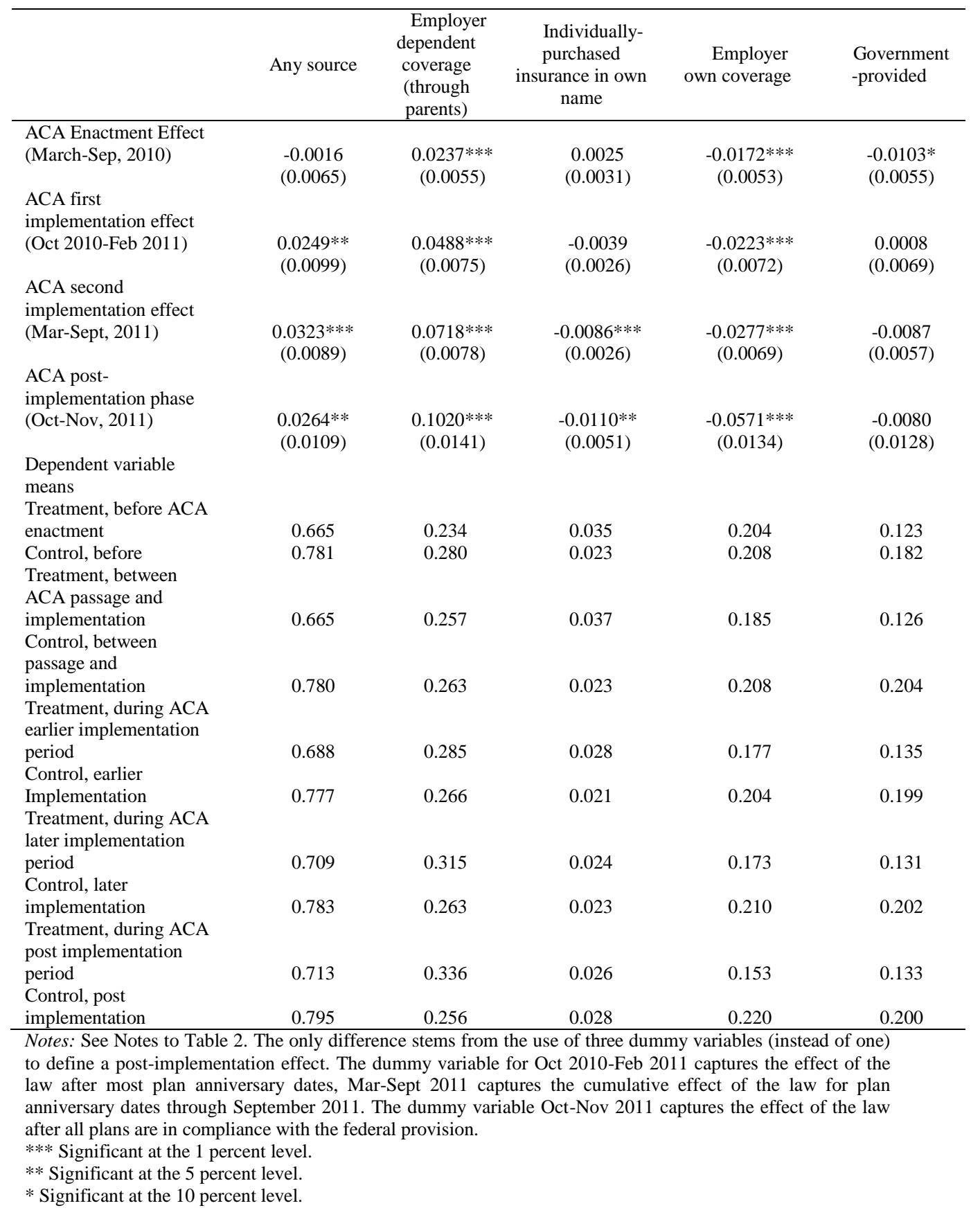


TABLE 4. EFFECT OF ACA ON COVERAgE OF Young Adults 19-25 YeARs: DD RESUlts by SubGROUPS

\begin{tabular}{|c|c|c|c|c|c|c|}
\hline & $\begin{array}{l}\text { Any } \\
\text { source }\end{array}$ & $\begin{array}{l}\text { Employer } \\
\text { dependent } \\
\text { coverage } \\
\text { (through } \\
\text { parents) }\end{array}$ & Any source & $\begin{array}{l}\text { Employer } \\
\text { dependent } \\
\text { coverage } \\
\text { (through } \\
\text { parents) }\end{array}$ & Any source & $\begin{array}{l}\text { Employer } \\
\text { dependent } \\
\text { coverage } \\
\text { (through } \\
\text { parents) }\end{array}$ \\
\hline by Age group & \multicolumn{2}{|c|}{$19-22$ years old } & \multicolumn{2}{|c|}{ 23-25 years old } & \multicolumn{2}{|c|}{ Difference } \\
\hline ACA enactment effect & $-0.0183^{*}$ & $0.0227 * * *$ & 0.0117 & $0.0153 * * *$ & $-0.0300 * *$ & 0.0074 \\
\hline ACA implementation effect & $0.0190 *$ & $0.0622 * * *$ & $0.0414 * * *$ & $0.0759 * * *$ & -0.0224 & -0.0137 \\
\hline by Gender & \multicolumn{2}{|c|}{ Male } & \multicolumn{2}{|c|}{ Female } & \multicolumn{2}{|c|}{ Difference } \\
\hline ACA enactment effect & 0.0059 & $0.0213 * *$ & -0.0085 & $0.0264 * * *$ & 0.0144 & -0.0051 \\
\hline ACA implementation effect & $0.0423 * * *$ & $0.0689 * * *$ & $0.0196 *$ & $0.0700 * * *$ & $0.0227 * *$ & -0.0011 \\
\hline by Race/Ethnicity & \multicolumn{2}{|c|}{ White } & \multicolumn{2}{|c|}{ Non-white } & \multicolumn{2}{|c|}{ Difference } \\
\hline ACA enactment effect & 0.0021 & $0.0216^{* * * *}$ & -0.0085 & $0.0253 * *$ & 0.0105 & -0.0037 \\
\hline ACA implementation effect & $0.0339 * * *$ & $0.0873 * * *$ & $0.0286^{* *}$ & $0.0420 * * *$ & 0.0053 & $0.0453 * * *$ \\
\hline by Marital status & \multicolumn{2}{|c|}{ Married } & \multicolumn{2}{|c|}{ Non-married } & \multicolumn{2}{|c|}{ Difference } \\
\hline ACA enactment effect & 0.0066 & 0.0055 & $\begin{array}{l}-0.0068 \\
\end{array}$ & $0.0220 * * *$ & 0.0134 & $-0.0165^{*}$ \\
\hline ACA implementation effect & 0.0097 & $0.0220^{* * *}$ & $0.0309 * * *$ & $0.0733 * * *$ & -0.0213 & $-0.0513^{* * *}$ \\
\hline by Student status & \multicolumn{2}{|c|}{ Full-time students } & \multicolumn{2}{|c|}{ Others } & \multicolumn{2}{|c|}{ Difference } \\
\hline ACA enactment effect & $-0.0174 * *$ & 0.0110 & 0.0041 & $0.0182 * * *$ & $-0.0215^{*}$ & -0.0072 \\
\hline ACA implementation effect & -0.0016 & $0.0340 * * *$ & $0.0481^{* * *}$ & $0.0763 * * *$ & $-0.0497 * * *$ & $-0.0423 * * *$ \\
\hline by Health status & \multicolumn{2}{|c|}{ "Excellent" } & \multicolumn{2}{|c|}{ Less than "excellent" } & \multicolumn{2}{|c|}{ Difference } \\
\hline ACA enactment effect & -0.0023 & $0.0293 * * *$ & -0.0043 & $0.0195 * *$ & 0.0020 & 0.0098 \\
\hline ACA implementation effect & $0.0274 * * *$ & $0.0780 * * *$ & $0.0354 * * *$ & $0.0673 * * *$ & -0.0080 & 0.0107 \\
\hline by State law status & \multicolumn{2}{|c|}{$\begin{array}{l}\text { States that enacted } \\
\text { laws }\end{array}$} & \multicolumn{2}{|c|}{$\begin{array}{l}\text { States that never enacted } \\
\text { laws }\end{array}$} & \multicolumn{2}{|c|}{ Difference } \\
\hline ACA enactment effect & -0.0025 & $0.0226^{* * *}$ & -0.0033 & $0.0284 * * *$ & 0.0008 & -0.0058 \\
\hline ACA implementation effect & $0.0291 * *$ & $0.0687 * * *$ & $0.0339 * * *$ & $0.0737 * * *$ & -0.0048 & -0.0050 \\
\hline
\end{tabular}

Notes: (1) Sample weighted estimates from 2008 SIPP panel data, using from August 2008 to November 2011.

(2) Dependent variables - columns 1 and 3: indicator variable that equals 1 if individual is covered by health insurance from any source and 0 otherwise; columns 2 and 4: indicator variable that equals 1 if individual is covered by employer health insurance as a dependent of a parent and 0 otherwise. (3) Other regressors are the same as those listed in Note (6) under Table 2, except that a demographic variable used to define subgroups is not included. (4) Columns 5 and 6 show the differences in effects between subgroups on the coverage through any source and employer health insurance coverage as a dependent, respectively. We obtain significance levels for the differences by testing the equality of coefficients using Seemingly Unrelated Regression methods. (5) See Notes (2)-(4) under Table 2.

*** Significant at the 1 percent level.

** Significant at the 5 percent level.

* Significant at the 10 percent level. 
TABle 5. EFFeCt of ACA on Coverage of Young Adults 19-25 YeARs: DDD Results Using PARENTAL INFORMATION

\begin{tabular}{|c|c|c|c|c|c|}
\hline & Any source & $\begin{array}{l}\text { Employer } \\
\text { dependent } \\
\text { coverage } \\
\text { (through } \\
\text { parents) } \\
\end{array}$ & $\begin{array}{l}\text { Individually } \\
\text { purchased } \\
\text { insurance in } \\
\text { own name }\end{array}$ & $\begin{array}{l}\text { Employer } \\
\text { own } \\
\text { coverage }\end{array}$ & $\begin{array}{l}\text { Government- } \\
\text { provided }\end{array}$ \\
\hline ACA enactment effect & $0.0392 * * *$ & 0.0135 & 0.0052 & -0.0121 & $0.0320^{*}$ \\
\hline (Mar-Sep, 2010) & $(0.0139)$ & $(0.0089)$ & $(0.0070)$ & $(0.0110)$ & $(0.0177)$ \\
\hline $\begin{array}{l}\text { ACA implementation effect } \\
\text { (Oct, 2010-) }\end{array}$ & $\begin{array}{l}0.0669 * * * \\
(0.0235)\end{array}$ & $\begin{array}{l}0.0961 * * * \\
(0.0104)\end{array}$ & $\begin{array}{l}-0.0131^{*} \\
(0.0067)\end{array}$ & $\begin{array}{l}-0.0245 \\
(0.0147)\end{array}$ & $\begin{array}{c}0.0132 \\
(0.0216)\end{array}$ \\
\hline \multicolumn{6}{|l|}{$\begin{array}{l}\text { Dependent variable means } \\
\text { Among those whose parents } \\
\text { do not have ESI }\end{array}$} \\
\hline $\begin{array}{l}\text { Treatment, before ACA } \\
\text { enactment }\end{array}$ & 0.435 & 0 & 0.031 & 0.104 & 0.215 \\
\hline Control, before & 0.658 & 0 & 0.017 & 0.064 & 0.479 \\
\hline $\begin{array}{l}\text { Treatment, after ACA } \\
\text { enactment }\end{array}$ & 0.461 & 0 & 0.032 & 0.103 & 0.234 \\
\hline $\begin{array}{l}\text { Control, after } \\
\text { Among those whose parents } \\
\text { have ESI }\end{array}$ & 0.684 & 0 & 0.017 & 0.075 & 0.499 \\
\hline $\begin{array}{l}\text { Treatment, before ACA } \\
\text { enactment }\end{array}$ & 0.793 & 0.525 & 0.032 & 0.154 & 0.054 \\
\hline Control, before & 0.912 & 0.715 & 0.015 & 0.075 & 0.081 \\
\hline $\begin{array}{l}\text { Treatment, after ACA } \\
\text { implementation }\end{array}$ & 0.857 & 0.603 & 0.021 & 0.145 & 0.056 \\
\hline Control, after & 0.903 & 0.674 & 0.017 & 0.100 & 0.083 \\
\hline \multicolumn{6}{|c|}{$\begin{array}{l}\text { Notes: (1) Number of observations is } 91,743 \text {. (2) Cells of the table contain: coefficients, and standard errors in } \\
\text { parentheses. Coefficients in the first row are from the interaction of a dummy variable for treatment group (19- } \\
25 \text { years old), a dummy variable for the period after ACA enactment but before implementation (March- } \\
\text { September, 2010) and a dummy variable that indicates that a parent has employer sponsored insurance; } \\
\text { coefficients in the second row are from the interaction of a dummy variable for treatment group, a dummy } \\
\text { variable for the period after ACA implementation (October } 2010 \text { and onwards) and a dummy variable that } \\
\text { indicates that a parent has employer sponsored insurance. (3) Data: pooled waves of the } 2008 \text { SIPP panel. We } \\
\text { use the data for period from August } 2008 \text { to November } 2011 \text {. The population is young adults aged from } 16-29 \\
\text { (except for the removal of } 26 \text { years olds) for whom parental information is available. Only 4th reference month } \\
\text { observations from the SIPP are used in the regression. (4) Other regressors are a dummy variable that indicates } \\
\text { that a parent has employer sponsored insurance, and its interactions with a dummy variable for the period after } \\
\text { ACA enactment but before ACA implementation, with a dummy variable for the period after ACA } \\
\text { implementation, and with a dummy variable for each year of age, and with year fixed effects, and all the } \\
\text { variables included in the DD regressions in Table } 2 \text {. (5) Means of dependent variables are obtained for } \\
\text { treatment and control groups before ACA enactment (before March } 2010 \text { ) and after ACA implementation (after } \\
\text { September 2010) for those whose parents do not have ESI and those whose parents do have ESI. (6) See also } \\
\text { Notes (3), (5), under Table } 2 \text {. } \\
\text { *** Significant at the } 1 \text { percent level. } \\
\text { ** Significant at the } 5 \text { percent level. } \\
* \text { Significant at the } 10 \text { percent level. }\end{array}$} \\
\hline
\end{tabular}


TABLE 6: Characteristics of Uninsured (But Eligible) Young Adults

\begin{tabular}{|c|c|c|c|}
\hline & $\begin{array}{c}\text { Employer } \\
\text { dependent } \\
\text { coverage } \\
\text { (through parents) }\end{array}$ & Uninsured & \\
\hline \multicolumn{4}{|l|}{ Employment status } \\
\hline Indicator: employed & 0.545 & 0.565 & \\
\hline Indicator: unemployed & 0.070 & 0.154 & $* * *$ \\
\hline \multicolumn{4}{|l|}{ Demographic characteristics } \\
\hline Age & 21.07 & 21.99 & $* * *$ \\
\hline Indicator: female & 0.487 & 0.371 & $* * *$ \\
\hline Indicator: white & 0.725 & 0.483 & $* * *$ \\
\hline Indicator: African-American & 0.090 & 0.173 & $* * *$ \\
\hline Indicator: Hispanic & 0.105 & 0.261 & $* * *$ \\
\hline Indicator: married & 0.018 & 0.053 & $* * *$ \\
\hline \multicolumn{4}{|l|}{ Education } \\
\hline Indicator: student & 0.613 & 0.267 & $* * *$ \\
\hline Indicator: less than high school & 0.032 & 0.086 & $* * *$ \\
\hline Indicator: high-school graduate & 0.285 & 0.429 & $* * *$ \\
\hline Indicator: some college & 0.565 & 0.442 & $* * *$ \\
\hline Indicator: college graduate & 0.109 & 0.037 & $* * *$ \\
\hline \multicolumn{4}{|l|}{ Income } \\
\hline $\begin{array}{l}\text { Family income as the ratio to federal poverty level } \\
\text { Health status }\end{array}$ & 5.114 & 3.028 & $* * *$ \\
\hline $\begin{array}{l}\text { Self-reported health is less than "excellent" } \\
\text { Living arrangement }\end{array}$ & 0.448 & 0.594 & $* * *$ \\
\hline Indicator: live with their parents & 0.955 & 0.915 & $* * *$ \\
\hline Number of observations & 2,055 & 429 & \\
\hline
\end{tabular}

Note: Data: the latest wave available from the 2008 SIPP panel (August to November 2011). The population is young adults (19-25 years old) whose parents had employer-sponsored health insurance. The last column indicates the level of statistical significance of the sample differences.

*** Significant at the 1 percent level.

** Significant at the 5 percent level.

* Significant at the 10 percent level. 
TABle 7. EFFeCt of ACA on Labor Market Outcome of Young Adults 19-25 Years: DD Results

\begin{tabular}{|c|c|c|c|c|c|c|c|}
\hline & $\begin{array}{l}\text { Probabil } \\
\text { ity of } \\
\text { being } \\
\text { employe } \\
\text { d }\end{array}$ & $\begin{array}{l}\text { Probability } \\
\text { of working } \\
\text { full time }\end{array}$ & Hours & $\begin{array}{l}\text { Log of } \\
\text { hours }\end{array}$ & $\begin{array}{l}\text { Probabili } \\
\text { ty of } \\
\text { changing } \\
\text { employe } \\
\text { rs or job } \\
\text { status }\end{array}$ & $\begin{array}{l}\text { Probabili } \\
\text { ty of } \\
\text { changing } \\
\text { employe } \\
\text { rs }\end{array}$ & $\begin{array}{l}\text { Probabilit } \\
\text { y of } \\
\text { having } \\
\text { hours that } \\
\text { vary }\end{array}$ \\
\hline \multicolumn{8}{|l|}{$\begin{array}{l}\text { ACA } \\
\text { enactment }\end{array}$} \\
\hline $\begin{array}{l}\text { effect (Mar- } \\
\text { Sep, 2010) }\end{array}$ & $\begin{array}{l}-0.0015 \\
(0.0062)\end{array}$ & $\begin{array}{c}-0.0154 * * \\
(0.0058)\end{array}$ & $\begin{array}{c}-0.474 * * \\
(0.233)\end{array}$ & $\begin{array}{c}-0.0268 \\
(0.0208)\end{array}$ & $\begin{array}{l}-0.0042 \\
(0.0042)\end{array}$ & $\begin{array}{l}-0.0017 \\
(0.0046)\end{array}$ & $\begin{array}{c}0.0141 * * * \\
(0.0047)\end{array}$ \\
\hline $\begin{array}{l}\text { ACA } \\
\text { implementati }\end{array}$ & & & & & & & \\
\hline $\begin{array}{l}\text { on effect } \\
\text { (Oct-, 2010) }\end{array}$ & $\begin{array}{c}-0.0058 \\
(0.0062)\end{array}$ & $\begin{array}{c}-0.0221 * * * \\
(0.0066)\end{array}$ & $\begin{array}{c}-0.807 * * * \\
(0.258)\end{array}$ & $\begin{array}{c}-0.0475^{* *} \\
(0.0213)\end{array}$ & $\begin{array}{c}0.0063 \\
(0.0046)\end{array}$ & $\begin{array}{c}0.0044 \\
(0.0037)\end{array}$ & $\begin{array}{r}0.0122 * * \\
(0.0059)\end{array}$ \\
\hline $\begin{array}{l}\text { Dependent } \\
\text { variable } \\
\text { means }\end{array}$ & & & & & & & \\
\hline $\begin{array}{l}\text { Treatment, } \\
\text { before ACA } \\
\text { enactment } \\
\text { Control, }\end{array}$ & 0.651 & 0.383 & 23.3 & 2.27 & 0.167 & 0.103 & 0.099 \\
\hline $\begin{array}{l}\text { before } \\
\text { Treatment, } \\
\text { after ACA } \\
\text { implementati }\end{array}$ & 0.524 & 0.306 & 17.8 & 1.73 & 0.112 & 0.063 & 0.080 \\
\hline & 0.602 & 0.340 & 20.4 & 2.04 & 0.149 & 0.099 & 0.099 \\
\hline $\begin{array}{l}\text { Control, } \\
\text { after }\end{array}$ & 0.481 & 0.293 & 16.0 & 1.56 & 0.088 & 0.053 & 0.066 \\
\hline
\end{tabular}

Notes: (1) Number of observations is 150,997 in the first, second and seventh columns, 137,841 in the third and fourth columns, and 120,301 in the fifth and sixth column. Observations in which individuals report work hours that vary are excluded in the regressions on hours and log of hours (columns 3 and 4). (2) Data: pooled waves of the 2008 SIPP panel. We use data for the period from August 2008 to November 2011. The population is young adults aged from 16-29, except for the removal of 26 year olds who are in neither control nor treatment. Only 4th reference month observations from the SIPP are used in the regression. (3) Dependent variables - column 1: indicator variable that equals 1 if individual is employed and 0 otherwise; column 2: indicator variable that equals 1 if individual works full time (twenty hours or more per week) and 0 otherwise; column 3: number of hours per week individual works; column 4: $\log$ of number of hours per week individual works; column 5: indicator variable that equals 1 if individual has work hours that vary and 0 otherwise. (4) See Notes (2),(3), (6) and (7) under Table 2.

*** Significant at the 1 percent level.

** Significant at the 5 percent level.

* Significant at the 10 percent level. 